\title{
VENTURING INTO NEW TERRITORY: CAREER EXPERIENCES OF CORPORATE VENTURE CAPITAL MANAGERS AND PRACTICE VARIATION
}

\author{
GINA DOKKO \\ University of California, Davis \\ VIBHA GABA \\ INSEAD, Singapore
}

\begin{abstract}
When organizations adopt new practices, the practices are often modified to fit the new context. We argue that managers who implement new practices modify them, and that the extent of practice variation is determined by two types of these managers' career experience: experience with the practice itself and experience that enables assessment of the fit between the practice and the adopting firm. We test these arguments by observing information technology firms' modification of venture capital practices in corporate venture capital units. This study contributes to diffusion research by developing and testing a framework for understanding the role of individuals in practice variation.
\end{abstract}

The diffusion of practices has long been a central concern of organization theory. The social, institutional, and structural mechanisms through which practices diffuse (e.g., Abrahamson \& Rosenkopf, 1997; Davis \& Greve, 1997; Palmer, Jennings, \& Zhou, 1993), and the conditions under which they are adopted or not (e.g., Ferlie, Fitzgerald, Wood, \& Hawkins, 2005; Jonsson, 2009) are becoming well understood. Yet, even in this rich literature, few studies have gone beyond the adoption event, instead assuming that practices are adopted uncritically and in toto (Campbell, 2005: 54). In contrast, qualitative accounts of practice adoption suggest that practices are not adopted wholesale but are typically modified to fit a new context (Ansari, Fiss, \& Zajac, 2010; Czarniawska-Joerges \& Sevón, 2005; Gaba \& Meyer, 2008). These modifications

We thank Matthew Bidwell, Beth Bechky, Diane Burton, Gary Dushnitsky, Kathy Eisenhardt, Henrich Greve, Alan Meyer, and seminar participants at NYU Stern OT/ Strategy Brownbag, West Coast Research Symposium on Technology Entrepreneurship, the Wharton People and Organizations Conference, and the Academy of Management meetings for their valuable comments. We also thank our associate/action editor, Jim Combs, for his generous support and guidance. Clare Lee, Spencer Doehlert, and Thijs Kwik provided valuable help with data collection. The research reported in this paper was supported by INSEAD research grant 2520-493R. Both authors contributed equally to this work.

Editor's note: The manuscript for this article was accepted for publication during the term of $A M J$ 's former editor-in-chief, R. Duane Ireland. are important to understand, because they may enable or impede persistence of a practice in particular organizations (e.g., Strang \& Jung, 2009), or they may result in innovation to the practice itself (Ansari et al., 2010). Therefore, scholars need to extend theory about diffusion to understand the sources of practice variation.

Institutional theory is an important lens through which researchers have examined practice diffusion (Strang \& Meyer, 1993; Strang \& Soule, 1998). Because institutional processes favor isomorphism, the theory plays down variation in organization-level adaptation to diffusing practices, and little attention has been devoted to the adaptation of practices as they are implemented in organizations (Lounsbury, 2008). Recent studies, however, acknowledge that heterogeneity in organizational practices is institutionally and organizationally shaped (Dacin, Goodstein, \& Scott, 2002; Lounsbury, 2008). For example, the presence of competing institutional logics or of broader fieldlevel organizations can lead to differences in how or which elements of practice are adopted (Lounsbury, 2001, 2007). Within organizations, political contestation and the framing of a practice can lead to variation in goal orientations and in how pervasively practices are incorporated (Fiss \& Zajac, 2004; Kennedy \& Fiss, 2009). These studies advance understanding of various field- and organization-level sources of variation; however, they do not address practice variation that results from individual-level action.

The translation perspective, offered by Scandinavian institutionalism, portrays a process view of practice variation in which practices are posited to 
undergo change every time they are applied in a new context (Czarniawska-Joerges \& Sevón, 2005; Sahlin \& Wedlin, 2008). Case studies based on this perspective show that individuals actively interpret and translate practices into a new context using editing rules that are governed by the institutionalized beliefs and norms of the new context or rules that contextualize broad ideas into concrete concepts that are easy to apply (e.g., Boxenbaum \& Battilana, 2005; Morris \& Lancaster, 2006). Although these studies' primary focus is on the intraorganizational processes underlying adaptation, they also document how individuals actively interpret and translate practices to fit into a new local context. However, they do not provide a systematic basis for making predictions about how individuals influence the extent of practice variation.

Therefore, existing theory does not address the extent of practice variation or provide a systematic way of understanding individuals' influence on modification of practices to fit the contexts of adopting organizations. We address these gaps by focusing on the role of individuals in practice variation. The individuals who implement and manage practices evaluate the fit of the practices to a context, and these individuals can influence the extent of practice variation. We draw on organizational learning theory that highlights individuals' knowledge and cognition and their effects on how individuals perceive problems and make choices (March \& Simon, 1958; Miner \& Mezias, 1996). Developments in this research stream show that the prior experiences of individuals are portable and condition what they know and how they see the world, which results in organization-level learning (Almeida, Dokko, \& Rosenkopf, 2003; Wezel, Cattani, \& Pennings, 2006), new product introduction (Rao \& Drazin, 2002), and models of organizing (Beckman \& Burton, 2008). Thus, we propose that practice variation is a function of the career experiences of the individuals who manage and implement adopted practices. Implementing managers' career experiences supply knowledge and skills and models of behavior or logics of action that affect managerial action and organizational outcomes (Burton, Sorensen, \& Beckman, 2002; Lant, Milliken, \& Batra, 1992).

We develop a theoretical framework that distinguishes between two relevant types of career experience: experience conducting a practice itself, and experience that enables assessment of the fit between a practice and an adopting organization. We argue that practice-specific and fit-specific career experiences provide individuals with specific knowledge and mental models that influence the extent to which practices are modified in adopting organizations. We test hypotheses generated from this framework in the context of corporate venture capital (CVC) units. CVC units are structurally distinct units established within existing corporations that are dedicated to making external equity investments in high-potential entrepreneurial start-ups (Gaba \& Meyer, 2008). These units are modeled on the venture capital practices of finding, funding, and guiding entrepreneurial start-ups. The implementation of these practices in a corporate context presents challenges based on the goals and operational methods of the practices as well as on idiosyncratic features of adopting firms, providing reasons for modifying these practices. In addition, differences in governance, compensation, and social structures deter the free flow of labor from independent venture capital (IVC) firms into CVC units, providing the variance in experiences of CVC managers that is needed to address our questions, and making CVC units a highly suitable context for studying questions about individual-level effects on practice variation.

We contribute to the diffusion literature by developing and testing theory about practice variation that highlights the role of individuals who implement practices and specifying how their career experience influences the extent of practice variation. In doing so, we complement work on institutional and organizational sources of practice variation by investigating its microfoundations.

\section{PRACTICE VARIATION WITHIN CVC UNITS}

Venture capital practices consist of selecting, funding through equity, and providing managerial support to young companies that have the potential to grow exponentially (Gompers \& Lerner, 2004). Established firms typically adopt venture capital practices by forming CVC units. In recent years, many technology firms have come to view CVC units as a crucial part of their R\&D and business development activities (Chesbrough, 2003). These units facilitate a coordinated and proactive approach to external sources of new technologies to complement or even replace in-house R\&D (Dushnitsky \& Lenox, 2005). The 1990s saw an unprecedented diffusion of CVC units: by the year 2001 over 300 U.S. firms had established corporate venturing units (Gaba \& Meyer, 2008). Simultaneously, the corporate share of overall venture capital investments rose from 2 percent in 1994 to 17 percent in 2000, according to Venture Economics (http:// ventureeconomics.com/).

Investigating questions about adaptation and fit in a CVC context entails specifying areas in which practice variation could occur. We focus specifi- 
cally on the venture capital practice of finding investment targets-that is, the evaluation and selection of start-ups, the critical first stage of the venture capital process (Gompers \& Lerner, 2004). Adapting this practice to a corporate context can entail modification of the goal orientation and the operational strategies concerning investments. First, venture capital practices are traditionally conducted in independent venture capital partnerships of professional investors whose central goal is to maximize financial returns on their investments (Gompers \& Lerner, 2004). To achieve this goal, IVCs typically invest in entrepreneurial startups that have innovative, but uncertain, product ideas. The IVCs use their expertise and specialized skills to help bring products to market quickly and "cash out" at an optimal point (Metrick \& Yasuda, 2010). For CVC units, venture capital practices that are oriented around identifying lucrative investment opportunities are complicated by the overlay of a strategic imperative. Although firms may be enticed by the potential for a financial "home run," most firms claim that their foremost objectives are strategic: learning about new (and potentially disruptive) technologies, gaining access to new markets and business models, and identifying prospective acquisition targets (Chesbrough, 2003). Thus, the goal orientation of CVC units can vary: they can be oriented toward purely financial goals, as in the case of IVCs; or they can be oriented toward strategic goals that contribute to an overall technology or business strategy; or they can be oriented toward both goals (MacMillan, Roberts, Livada, \& Wang, 2008).

Second, IVCs follow certain typical operational strategies for selecting investment targets. Two important operational choices that IVCs make are investment timing and range of investment targets (Gompers \& Lerner, 2004). Though IVCs can invest in different stages of a start-up's life, they tend to invest early because they hold an advantage over other investors in the earlier stages. Early-stage start-ups are often little more than an idea and a founding team, and IVCs have the specialized knowledge and skills needed to evaluate start-ups at this stage of development. In addition, IVCs tend to have extensive social networks that cross industry boundaries (Sorenson \& Stuart, 2001), giving them information about, and access to, a wider scope of investment opportunities than other investors have. Given their expertise, IVCs concentrate investments where "information asymmetries" are likely to be most significant and monitoring most valuable; specifically, they tend to follow operational strategies of investing in early-stage companies and in a variety of industries (Gompers, 1995).
CVC units can follow standard IVC investment strategies by investing early in start-ups, or they can invest later, when the uncertainty about the start-ups' technologies and business models is greatly reduced. Similarly, CVC units can vary from IVCs in terms of investment range by restricting their exploration of investment targets to a narrower range of start-ups that are more targeted to the firm's strategic needs.

Therefore, implementing the IVC practice of evaluating and selecting investments in CVC units can entail adjustment in both the practice's goal orientation and operational strategies.

\section{THEORY AND HYPOTHESES}

What are the sources of practice variation, and in what ways do practices vary? Institutional scholars acknowledge the connection between institutional context and variation in organizational behavior and practices. For instance, Lounsbury (2007) found that competing logics within the mutual fund industry led to contestation over goal orientation and variance in the use of professional money management firms. Alternatively, practice variation can be shaped by organizational and technical fit between diffusing practices and adopting organizations (Ansari et al., 2010; Meyer \& Goes, 1988). Moreover, pressures for customization can be particularly intense when innovative practices are adopted from a different organizational population (Gaba \& Meyer, 2008). The translation perspective on practice adoption highlights the process by which practices are actively translated and edited to fit a local context (e.g., Czarniawska-Joerges \& Sevón, 2005; Sahlin-Andersson, 1996). This perspective draws on the concept of theorization (Gaba \& Meyer, 2008; Nigam \& Ocasio, 2010; Strang \& Meyer, 1993), which entails "translating concrete practices into abstractions for export and then unpacking the abstractions into a (suitably modified) concrete practice upon arrival" (Strang \& Soule, 1998: 276). Critical to the translation process is how practices become reinterpreted and then applied in a new setting. In theory about the postadoption processes that lead to variation, adopting firms locally "construct" the problems and needs that trigger adoption in the first place, and this construction is used to change practices to fit (Sahlin-Andersson, 1996).

Therefore, practices can be modified as they are implemented in organizations, leading to variation in the way practices are conducted. First, the process of translation can lead to changes in the goals of a practice itself. For example, Boxenbaum and Battilana (2005) examined the diffusion of Ameri- 
can-style diversity programs from the U.S. to Denmark. They found that as these programs diffused, the goals of the program changed from increasing organizational and individual effectiveness to enhancing the integration of immigrants into the Danish workforce. Likewise, Gaba and Meyer (2008) observed that the diffusion of venture capital practices among publicly traded corporations was accompanied by the modification of the practice's goals from pursuing purely financial returns to accessing new and emerging technologies. Second, the operational methods of practices can also come to vary as the practices are implemented in organizations (e.g., Morris \& Lancaster, 2006; Zbaracki, 1998). For example, though sophisticated statistical tools are an important part of total quality management (TQM) practice, Zbaracki (1998) details how managers implementing TQM avoided statistical tools that they found intimidating or difficult to understand, using them symbolically or marginally, or dropping them from the practice altogether. Similarly, Coburn (2004) found that public school teachers' individual prior experiences with reading instruction mediated between the adoption of new practices for reading instruction and the routines, materials, and organization that constituted the practices in their specific classrooms.

In sum, prior research has investigated field- or organization-level sources of practice variation and how practices can be translated and edited into the language and logics of a new context. Despite these advances in scholars' understanding of the sources of practice variation, individuals' roles in modifying practices remain largely unaddressed. A number of the studies cited above (i.e., Boxenbaum \& Battilana, 2005; Coburn, 2004; Morris \& Lancaster, 2006; Zbaracki, 1998) are detailed qualitative accounts that suggest that individual-level effects also operate on practice variation. However, they do not provide a systematic way of predicting how much individuals influence the extent of practice variation.

\section{Implementing Manager's Career Experience and Practice Variation}

Managers who perform practices are the interpreters and editors of adopted practices (Boxenbaum \& Jonsson, 2008; Sahlin-Andersson, 1996). They make choices about what aspects of practices to implement and in what way practices will be modified (i.e., what goals and operational strategies will be pursued). Though an adopting organization sets some of these directions, individuals bring their own expertise, preferences, and cognitions to the task of implementing and operating a new prac- tice, and these characteristics are a function of their career experience. There is ample evidence that career experience affects what individuals know, the way in which they perceive the world, and how they act. Organizational learning scholars consider prior career experience an important source of learning, theorizing that experience carried by individuals influences firm-level innovation or change (Beckman \& Burton, 2008; Rao \& Drazin, 2002; Singh \& Agrawal, 2011) and individual and team performance (Boh, Slaughter, \& Espinosa, 2007; Dokko, Wilk, \& Rothbard, 2009). In doing so, these authors rely on two common mechanisms that account for the effects of prior experience: specific knowledge and mental models.

Specific knowledge gained from individuals' prior jobs is one way in which career experience can affect practice variation. Specific knowledge, by which we mean knowledge and skill tailored to a particular environment or set of tasks, affects both what individuals are able to do and how they define problems (Carlile, 2004). First, specific knowledge enables the successful performance of tasks associated with a practice or type of work (Argote, 1999). For instance, entrepreneurs who have previous experience with firm founding acquire specific knowledge about the practices of founding new ventures that enables them to repeat the process (Shane \& Khurana, 2003). In addition, career experience can confer specific knowledge about social environments. For example, firm-specific knowledge includes an understanding of a firm's culture, politics, and routines that affects managerial actions and outcomes (Groysberg, Lee, \& Nanda, 2008; Huckman \& Pisano, 2006). Second, specific knowledge affects how managers understand problems by creating a reference point for interpreting situations in relation to their expertise. Elements of a situation that are familiar are more salient, which encourages individuals to interpret a problem in terms of what they know (Lant et al., 1992). Mental models are a second, related mechanism through which career experience affects practice variation. Mental models reflect the way individuals see the world: the causal models they hold about performance and their assumptions about what goals and behavior are appropriate and valued (March \& Simon, 1958). Individuals base these models on their prior experiences (Dokko et al., 2009; Kraatz \& Moore, 2002). The operation of mental models is primarily nondeliberative (Gioia \& Poole, 1984), in such a way that taken-for-granted assumptions affect choices about what tasks and goals are most important for an organization.

In explaining the extent of practice variation, we focus on implementing managers' career experi- 
ence that is oriented either toward an adopted practice, or toward its fit with the adopting firm. Though the career experience of implementing managers has not been directly applied to predicting the extent of practice variation, we expect the mechanisms of specific knowledge and mental models to operate in this relationship as well. As individuals implement and manage practices, they interpret problems, prioritize activities and goals, and conduct work according to their prior experience. Our framework thus distinguishes between two types of experiences held by implementing managers: practice-specific experience, defined as prior career experience performing a practice, and fit-specific experience, defined as prior career experience that enables assessment of fit between a practice and organizational or technical aspects of an adopting organization. We use this distinction to hypothesize the impact of implementing managers' prior career experiences on the extent of practice variation, in terms of both the goal orientation and operational strategies of the adopted practices.

\section{Practice-Specific Experience and Practice Variation}

Career experience with a practice yields specific knowledge about the activities that comprise the practice itself. This specific knowledge should lead implementing managers to perceive the postadoption process as a problem of straightforward application of their previous experience with a practice and to perform the activities in a way that is familiar to them (Dokko et al., 2009). Reinforcing this effect, these managers also tend to view their ac- customed goals and familiar ways of performing the practice as appropriate, because of the mental models they hold from their experience with the practice (Gioia \& Poole, 1984; Kraatz \& Moore, 2002). Accordingly, implementing managers' practice-specific experience should lead to less variation in both the goal orientation and the operational strategies of the practice as implemented in a new context.

For managers in CVC units, having prior experience with venture capital practices in IVC firms should lead them to apply their experience in a straightforward way that minimizes practice variation. That is, CVC managers with career experience in IVCs should be oriented toward financial goals, as they are both knowledgeable about how to attain financial goals and conditioned to value those goals. Operationally, they are likely to apply their knowledge about evaluating early-stage start-ups to their strategy for an investment stage and to invest in a relatively industry-agnostic way, as IVCs do, influencing the selection of investment targets of the CVC unit. This propensity to act in accordance with prior experience should lead to less variation from standard IVC practice when implementing managers have IVC experience.

Hypothesis 1a. The higher the proportion of implementing managers who have practicespecific experience (i.e., career experience in IVCs), the less a practice's goal orientation is modified when it is adopted.

Hypothesis $1 b$. The higher the proportion of implementing managers who have practice-

FIGURE 1

Implementing Managers' Career Experience and Extent of Practice Variation

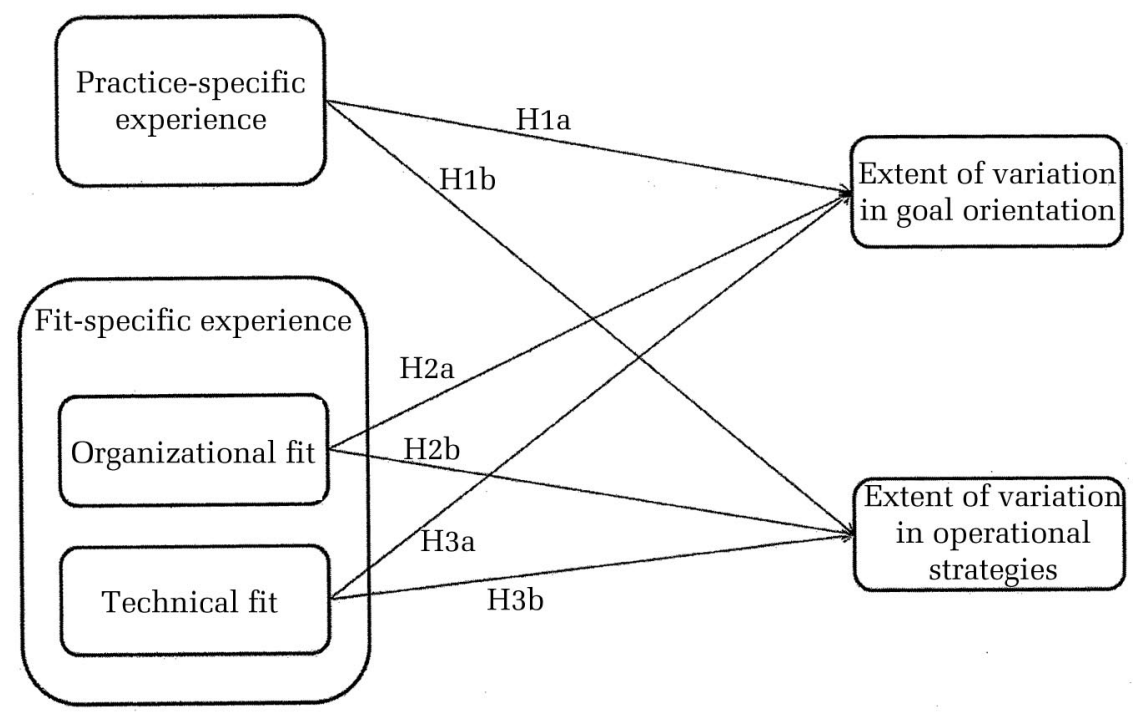


specific experience (i.e., career experience in IVCs), the less a practice's operational strategies are modified when it is adopted.

\section{Fit-Specific Experience and Practice Variation}

In addition to practice-specific experience, implementing managers may also have experiences that can inform their assessment of the fit between a practice and an adopting organization. Like deep understanding of the practice, deep understanding of an adopter's objectives and social environment or of its existing systems and technologies as they relate to an adopted practice can drive customization of a newly adopted practice (Ansari et al., 2010; Birkinshaw, Hamel, \& Mol, 2008; Meyer \& Goes, 1988). We distinguish two types of experience that affect implementing managers' assessment of the fit between a practice and an adopting organization. Organizational fit-specific experience focuses on fit between a practice and organizational (i.e., strategic, cultural, and political) aspects of an adopting organization, and technical fit-specific experience focuses on fit between technical aspects of a practice and systems and technologies that an organization already uses.

Organizational fit-specific experience. Assessing the organizational fit of a practice entails considering the practice in terms of its compatibility with the existing social environment and business strategies of an adopting firm. Organizational insiders have firm-specific knowledge that enables understanding of the cultural, political, and strategic context that a practice must operate in (Groysberg et al., 2008; Huckman \& Pisano, 2006). Moreover, an individual who has been socialized into an organization has internalized its culture (Van Maanen \& Schein, 1979), so that the mental models associated with organizational membership will also drive assessments of fit (Dokko et al., 2009). Additionally, implementing managers who are already organization members are more likely to understand the impetus for adopting a practice and how the practice fits with the organization's overall business strategy. Therefore, implementing managers who have career experience in the adopting organization, regardless of what function they previously performed, will likely see differences between a canonical version of a practice and the objectives and social environment of an organization that lead them to customize a practice.

In the context of CVC units, internally hired CVC managers should be more likely to modify practices to fit an adopting organization. Understanding a CVC unit's genesis and how it relates to the corporation's overall business strategy, culture, and ex- isting power structures will lead these managers to customize the goal orientation and operational strategies of their CVC unit, resulting in greater practice variation. Specifically, implementing managers who previously held other jobs in the adopting firm are more likely to modify investment goals to be oriented toward strategic goals instead of financial goals, and they are more likely to modify operational strategies for investing by favoring later-stage investing and investing in a narrower range of industries than IVCs would do.

Hypothesis 2a. The higher the proportion of implementing managers who have organizational fit-specific experience (i.e., firm-specific career experience), the more a practice's goal orientation is modified when it is adopted.

Hypothesis 2b. The higher the proportion of implementing managers who have organizational fit-specific experience (i.e., firm-specific career experience), the more a practice's operational strategies are modified when it is adopted.

Technical fit-specific experience. Individuals implementing adopted practices can also influence the extent of practice variation if they have career experience that enables assessment of the technical fit between a practice and an adopting organization. The technical dimension of fit concerns "the degree to which the characteristics of a practice are compatible with technologies already in use by potential adopters" (Ansari et al., 2010: 75). An organization's existing technologies may need to interact with technical aspects of a practice, and specific knowledge and mental models coming from prior experience that is related to these existing technologies influence fit assessment, whether or not the technical experience was acquired within the adopting organization. For instance, the widespread adoption of internet e-commerce practices by traditional corporations could be understood in terms of organizational strategy, politics, and culture, but it could also be considered in terms of a firm's existing technical systems for sales, inventories, and distribution. In this case, an implementing manager with experience in these technical systems, such as an enterprise resource planning (ERP) system expert, would have a refined understanding of technical fit, whether or not the ERP experience was with the adopting firm. Moreover, day-to-day choices that make up the operational strategies of an adopted practice are especially conditioned by the understanding of an organization's technical needs (Dewar \& Dutton, 1986). Therefore, we expect implementing managers who have technical 
fit-specific experience to be more likely to tailor practices to fit because of their superior understanding of the existing technologies and technical needs of the adopting firm and how they will interact with technical aspects of the practice.

In the case of CVC units, investments are typically made in high-technology start-ups, and the ability to understand an adopting firm's technological base and assess fit with start-ups' technologies can be a source of practice variation. The better a CVC manager understands an adopting firm's technologies and R\&D-related goals (e.g., by drawing on prior engineering experience), the less likely that manager will see an off-the-shelf version of a practice as a fit. Therefore, CVC managers who have engineering career experience will be more likely to modify IVC practices in such a way that investments are more strategically oriented and operational strategies target later-stage investment and more narrowly targeted industries.

Hypothesis 3a. The higher the proportion of implementing managers who have technical fit-specific experience (i.e., engineering career experience), the more a practice's goal orientation is modified when it is adopted at a CVC.

Hypothesis 3b. The higher the proportion of implementing managers who have technical fit-specific experience (i.e., engineering career experience), the more a practice's operational strategies are modified when the practice is adopted at a CVC.

It is important to note that managers can come to jobs having had multiple jobs and even multiple careers (Arthur \& Rousseau, 1996; Bidwell \& Briscoe, 2010); for example, CVC managers can have both IVC and engineering experience, or they can have held engineering jobs inside and outside of an adopting firm in their careers. ${ }^{1}$ Conceptually, and in the empirical analysis, we consider these types of experience in separate dimensions; for example, a manager with engineering experience within an adopting firm has both organizational and technical fit-specific experience.

\section{METHODS}

\section{Sample and Data}

We constructed our sample using the 2000, 2001, and 2002 volumes of the Corporate Venturing Yearbook and Directory, which lists firms with an active

\footnotetext{
${ }^{1}$ In our sample, only 50 percent of internal hires had engineering career experience.
}

CVC unit along with information about the year of establishment of the CVC unit. Though some IT firms experiment with CVC activity prior to establishing a formal unit, it is establishment-that is, the adoption of venture capital practices as a formal and staffed activity of the corporation-that is our starting event of interest, because it represents the starting point for adaptation of IVC practices. We restricted our sample to include only IT sector firms that had established CVC units. ${ }^{2}$ This procedure resulted in a sample of 93 IT firms with CVC units. IT firms were an appropriate sample for testing our hypotheses, because firms in the IT sector made more than three-quarters of all CVC investments in the 1990s (Gaba \& Meyer, 2008). Moreover, focusing on IT firms exclusively allowed us to control for unobserved heterogeneity at the industry level.

Next, we used the VentureXpert database to collect longitudinal data on the goal orientation and operational strategies of all CVC units in our sample until the year 2008. For CVC unit managers' prior experience, we collected biographical data through internet searches.

Because some data were missing from VentureXpert, or biographical information was incomplete, our final sample is an unbalanced panel for 70 CVC units over the period $1992-2008 .^{3}$

\section{Dependent Variables}

We constructed and tracked each CVC unit's portfolio of entrepreneurial start-ups to calculate time-varying measures of $C V C$ goal orientation and CVC operational strategies. We used VentureXpert to collect data on each CVC unit's portfolio of investments in U.S.-based entrepreneurial start-ups from the date of establishment of the unit up until the year 2008. The 70 firms in our final sample invested in 1,788 start-ups over the time period of our study. VentureXpert classifies each start-up as

\footnotetext{
${ }^{2}$ We used the National Science Foundation's definition of the IT sector (NSF, 2000) as comprising the following five industry subsectors: (1) Office, Computing and Accounting Equipment (SIC code 357), (2) Communications Equipment (SIC code 366) (3) Electronic Components (SIC code 367), (4) Communication Services (SIC codes 481-484, 489), (5) Computing and Data Processing Services (SIC code 737).

${ }^{3}$ At each stage at which our sample was reduced, we performed nonparametric Kolmogorov-Smirnov tests to check if the distribution of the firm-level variables significantly differed for the dropped firms as compared to the final sample of 70 firms. In all cases, the null of no significant difference is not rejected.
} 
"defunct," “private," "public," and "subsidiary." Each start-up enters a CVC unit's portfolio on the date of first investment and continues to be part of the portfolio as long as it is classified as active. Start-ups classified as public or subsidiary exit the portfolio the year after they went public or were acquired. We used SDC's Global Issues Database to identify the year in which a start-up went public and SDC's Mergers \& Acquisitions Database to identify the year a start-up was acquired. For startups classified as defunct, we dropped them from the portfolio only if at least two years had elapsed since the year they received their last round of financing. Overall, of the 1,778 start-ups that received investments from our sample of CVC units, 32 percent remained private, 11 percent went public, 40 percent were acquired, and 17 percent were defunct. $^{4}$

CVC goal orientation. To examine how much CVC units modify the goals of venture capital practices, we measured each CVC unit's goal orientation along two dimensions: financial and strategic. Financial orientation is the proportion of start-ups in a portfolio that resulted in an initial public offering (IPO) or an acquisition by a firm other than the parent of the focal CVC unit. For each CVC unit for each year, our measure cumulates all IPOs and acquisitions and expresses this sum as a fraction of the cumulated entrepreneurial start-ups in the portfolio. ${ }^{5}$ IPOs and acquisitions by other firms are cash-generating events, and they represent an orientation toward financial goals that are not necessarily strategically relevant for the CVC unit's parent firm, so we used these to represent an orientation toward financial goals. Since traditional VC practices are financially oriented, a high fraction of IPOs and acquisitions in a CVC unit's portfolio implies less modification of the original practice. The mean value for this variable is 0.28 , which implies that the average CVC unit had 28 percent of the start-ups it invested in either going public or being acquired by other firms.

\footnotetext{
${ }^{4}$ Of all the start-ups classified as defunct, 97 percent had not received any funding for a period greater than or equal to five years. For the remaining 3 percent, we checked through LexisNexis and internet sources and were able to confirm that these were indeed defunct start-ups. However, classifying them as private does not affect our results qualitatively.

${ }^{5}$ Our measure would be subject to bias if the proportion of companies that had an IPO or acquisition were expressed as a fraction of the number of active companies in a CVC unit's portfolio. By disregarding the companies that became defunct, we would overstate the degree of financial orientation.
}

We measured strategic orientation as the cumulated number of entrepreneurial start-ups acquired by the parent firm of a focal CVC unit as a proportion of all entrepreneurial start-ups in the CVC unit's portfolio since the unit's establishment (Benson \& Ziedonis, 2010; Gaba \& Meyer, 2008). As with our measure for financial orientation, we took the achievement of strategically relevant outcomes as a measure of the extent of CVC managers' orientation toward strategic goals. Consequently, a higher fraction of start-ups acquired by a parent firm indicates a divergence from the traditional financial goal orientation of IVCs. Though acquiring portfolio companies may not capture all strategic objectives of CVC investment, and acquisitions may even destroy shareholder value for firms that do not have dedicated CVC units (Benson \& Ziedonis, 2010), the very act of acquisition is a visible and tangible indicator of a CVC unit's belief about the potential strategic benefits that could accrue from such an acquisition.

We constructed this variable using the Securities Data Corporation's (SDC) Mergers \& Acquisitions database to obtain a list of all private acquisitions by the firms in our sample, then matched these acquisitions with each CVC investment in the VentureXpert database to include only those acquisition targets in which the CVC unit had invested prior to acquiring it. Our summary statistics show that the average CVC unit, in any given year, had acquired 2 percent of the portfolio companies that it invested in. ${ }^{6}$

The operationalizations of these dependent constructs are imperfect in that they do not directly measure CVC units' goal orientations and instead use investment outcomes as proxies. These proxies represent the dependent constructs to the extent that CVC units have varying goal orientations, and their investment outcomes reflect these orientations. Surveys of CVC units support variation in goal orientation. An Ernst \& Young (2008) survey of 37 CVC units found that 17 percent of them had purely strategic goals, 3 percent had purely financial goals, and the remaining 80 percent had a blend of financial and strategic goals. Similarly, a U.S. NIST report describes a study of 48 CVC units, of which 15 percent had only financial goals, 15 percent had only strategic goals, and 70 percent had both financial and strategic goals (MacMillan

\footnotetext{
${ }^{6}$ Since both financial and strategic orientation variables are expressed as proportions, right censoring is less of an issue. Firms that have a longer time to exit a portfolio company also have had a large number of portfolio companies at risk of exit.
} 
et al., 2008). We included separate dependent variables for financial and strategic goal orientation to allow for split orientation. Moreover, though investments are subject to review and approval by their corporate parent, CVC unit managers select the set of potential investment targets to be evaluated, and perform due diligence and make recommendations. Therefore, CVC units have orientations toward particular goals, and on average, orientation toward financial (strategic) goals should be associated with financially (strategically) oriented outcomes, making our dependent variables suitable proxies for goal orientation. In addition, these measures have the advantage of being independently observable and measurable, and they are also time-varying, which allowed us to estimate coefficients with greater precision using panel methods. Despite being suitable, using proxy measures introduces the possibility of measurement error. However, measurement error in the dependent variable does not bias estimates. It simply results in higher asymptotic variance that inflates standard errors (Wooldridge, 2002).

CVC operational strategies. We focused on two operational strategies that are closely associated with traditional venture capital practices: the proportion of early-stage investments in a CVC unit's portfolio and the diversity of investments in the CVC unit's portfolio. VentureXpert classifies investment in entrepreneurial start-ups according to the following stages: "seed," "early stage," "expansion," "later stage," "acquisition," and "public market." Proportion of early-stage investments is the number of investments classified as seed or early stage expressed as a proportion of all start-ups in a CVC unit's portfolio. In our sample, 20 percent of all investments in start-ups were classified as early stage ones. Next, to measure the range of industries invested in by a CVC unit, we calculated the sectoral diversification of investments. We identified the industry sector of each start-up receiving CVC funds using the Venture Economics Industry Classification (VEIC), a VentureXpert proprietary industry classification scheme. ${ }^{7}$ From this, we calculated a Herfindahl-Hirschman index of concentration as

$$
H H I_{i t}=\sum_{j} P_{i j t}^{2},
$$

where $P_{i t j}$ is the proportion of start-ups in firm i's CVC unit in industry-sector $j$ at time $t$. Since this is

\footnotetext{
${ }^{7}$ Since these portfolio companies are not publicly traded, they are not required to report traditional industry classifications such as SIC or NAICS codes. See Dushnitsky and Shaver (2009) for more details.
}

an inverse measure of diversification, to facilitate interpretation of coefficients, we recoded it as (1 $\left.H H I_{i t}\right)$.

\section{Independent Variables}

The major predictor variables in this study pertain to CVC managers' career experience. We collected biographical data on CVC personnel using internet-based searches conducted between November 2008 and July 2010. The Corporate Venturing Yearbook and Directory that we used to construct our firm-level sample also identifies the names of key personnel in the CVC units. The 93 CVC units in our sample were associated with 340 individuals, whom we uniquely identified using their names and the name of their CVC unit. Although biographical information is not universally or consistently available online, we were able to find at least some biographical information for 91 percent of them (311 individuals). Common sources of biographies were firm websites, Securities and Exchange Commission filings, and professional networking sites such as LinkedIn. Individuals could be missing from our sample because published biographies could not be found, or because their names were so common they could not be uniquely identified (e.g., "Mike Smith"). In addition, multiple biographical sources were found for many of the individuals in the database. Though most of the sources contained the same information about prior experience, when sources contained unique information, we recorded them separately. We recorded 773 separate biographies for the 311 managers.

For each manager, we reconstructed work history, listing each job separately and recording dates of employment or chronological ordering where available. We listed a separate job record for each different job title. This coding resulted in 1,565 separate job records. Because we collected data well after the 2000-02 sample time frame, we identified whether these jobs occurred before or after the CVC job identified in the Corporate Venturing Yearbook and Directory. Of the 1,565 jobs we identified, 845 jobs preceded the CVC jobs, 375 jobs were held after the CVC job, and the remaining 345 job records represented the CVC job. ${ }^{8}$ The 845 prior jobs were coded to capture different types of experience; this coding was the basis of our independent variables. Note that because coding is done at

\footnotetext{
${ }^{8}$ Some individuals had multiple job titles during their tenure in a CVC unit; e.g., one person went from "business development manager" to "investment manager."
} 
the job level, a single CVC manager could have multiple types of experience, i.e., he or she could have practice-specific and both types of fit-specific experience.

Where dates of employment for the CVC job were available, we developed variables that captured the experience of managers in each CVC unit over time. Start and end dates for CVC unit jobs were available for 229 individuals (74 percent of the 311 managers). An additional 41 managers' biographies listed either the start or end date for their CVC job. Common reasons for end dates to be available while start dates were not are that biographies tend to be more specific about recent jobs than about jobs in the more distant past, or that the job immediately following the CVC job provided information on its start date. For these reasons, we supplemented the sample by assuming that the manager started in the CVC job the first year his or her name appeared in the Directory. If start dates were available but end dates were missing, the reasons were less clear, as this condition generally resulted from the absence of recent biographies on the manager. Therefore, we assumed that the manager left the CVC job just after the last year his or her name appeared in the Directory. With these assumptions, the analysis sample increased to 270 managers (87 percent of the 311 managers).

Practice-specific career experience. We operationalized practice-specific experience as the proportion of personnel in a CVC unit who had prior experience in independent venture capital (IVC) firms. As part of the job-level coding, we coded IVC experience for each person by examining job titles and employers for prior jobs. For example, a general partner position at Frontier Ventures was coded as an IVC job. We created annual panels for proportions of CVC personnel with practice-specific career experience using the CVC job start and end dates.

Fit-specific career experience. We operationalized fit-specific career experiences in two ways: as firm-specific experience and as engineering experience. CVC managers who had prior career experience in an adopting firm were considered to have firm-specific career experience. In our data, these were all internal hires-that is, the job immediately preceding their first CVC job was in the adopting firm. The variable fit-specific experience-organizational measures the proportion of CVC personnel who were internal hires in the CVC units. Next, personnel with an engineering background have relevant experience to assess the technical fit between CVC practices and the adopting firm. Fitspecific experience-technical measures the proportion of CVC personnel who have engineering work experience or an engineering degree. For both measures, we created annual proportions using the CVC job start and end dates for the managers.

\section{Controls}

Firm-level controls. We included a number of firm-level controls that could account for the goal orientation and operational strategies of the CVC units. First, we controlled for firm size, using data on firm sales. Larger firms have more resources that can be allocated to CVC units, which may result in more investment alternatives or higher-quality employees. On the other hand, large firms are also encumbered by structural constraints that can discourage the pursuit of risky courses of action (Audia \& Greve, 2006). Though we do not predict a direction for firm size's effect, we control for it. Second, firms that exhibit better performance may attract higher-caliber personnel, who might adapt practices differently from lower-caliber personnel. Better-performing firms also tend to have a greater appetite for risk (March \& Shapira, 1987), which could influence their operational strategies. Therefore, we controlled for firm performance as income before extraordinary items plus depreciation. Third, firm age is associated with increases in rates of innovation (Sorensen \& Stuart, 2000). However, older firms can also find it difficult to keep up with externally generated technical changes and exhibit greater inertia (Abernathy \& Utterback, 1978). Firm age was the age of a firm in years at the time of CVC unit establishment. Finally, firms with greater slack resources are more likely to experiment in pursuit of new opportunities (Levinthal \& March, 1981) and may find it easier to invest in riskier early-stage start-ups, and to invest in a broader range of portfolio start-ups. Accordingly, we controlled for firm slack, measured as a firm's current ratio (the ratio of current assets to liabilities), which represents the liquid resources uncommitted to liabilities (Bromiley, 1991). ${ }^{9}$

CVC unit controls. We also controlled for CVC unit characteristics that might influence CVC goal orientation or operational strategies. For example,

\footnotetext{
${ }^{9}$ We also tested alternate measures of slack: absorbed slack, measured as the ratio of sales, general, and administrative expenses to sales; and potential slack, measured as the debt-to-equity ratio. Other controls we considered included an alternate measure of firm size (measured as firm assets), firm R\&D intensity, and dummies for a firm's primary SIC codes intended to capture technological differences. None of these variables were significant, and we did not include them in the final specification to conserve degrees of freedom.
} 
CVC units with more extensive operations and those that have been in operation longer are more likely to have invested in a broader range of industry sectors. Therefore, we controlled for CVC experience by including the cumulated number of startups each CVC unit had invested in since its establishment year. CVC duration was a count of the number of years since the date of the first investment made by a CVC unit. Since seven firms in our sample had invested in portfolio companies prior to the year of CVC unit establishment listed in the Directory, we used the time elapsed since the date of first investment (rather than the year of establishment) to construct this variable. ${ }^{10}$

Firm-specific fixed effects and temporal controls. Multiple omitted unobserved variables have the potential to confound hypothesis testing. We accounted for such influences by employing a methodology that explicitly accounts for firm fixed effects. Since the venture capital industry goes through episodic boom and bust cycles (Gompers \& Lerner, 2004), we included time dummies in all specifications to capture conditions in the overall public equity market.

Table 1 provides the summary statistics and correlations for the variables.

\footnotetext{
${ }^{10}$ In addition to these controls, we also examined the business education background of the personnel in CVC units. We found that CVC units with a greater proportion of personnel with business degrees were more strategically oriented and less financially oriented and, although less diversified, more likely to invest in early-stage companies. However, this control does not affect any of our main results in terms of the direction, significance, or magnitude of the coefficients.
}

\section{Empirical Methodology}

In our empirical estimation, we needed to address two issues. First, since all of our dependent variables were measured using a firm's portfolio of start-ups, changes in CVC practices may not be readily apparent unless a CVC unit significantly alters its portfolio. More importantly, there may be "path dependence," wherein decisions made by the CVC unit to change CVC practices going forward are conditional on the characteristics of the current CVC investment portfolio. Second, a shift in CVC unit personnel is likely to manifest itself as changes in CVC practices only over time, since identifying and investing in entrepreneurial start-ups is a timeconsuming process. This, in turn, implies the need to distinguish between short- and long-term effects of changes in CVC unit personnel.

We accounted for these concerns by including a lagged dependent variable as an independent regressor in each of our empirical models. This approach has several methodological advantages. First, it allows us to explicitly account for persistence and path dependence in CVC practices. Second, it allows us to estimate both a short-term contemporaneous effect for changes in the independent variable and a long-term steady-state effect. Third, the lagged dependent variable helps us to deal with the autocorrelation in panel data that can lead to incorrect estimates of the standard errors (Wooldridge, 2002). Finally, the lagged dependent variable can be recast as a geometrically weighted summary measure of all lagged CVC unit background variables whose effects decline over time (Greene, 2000). Therefore, it also allowed us to model past unobserved shocks as affecting future

TABLE 1

Summary Statistics and Correlations ${ }^{\text {a }}$

\begin{tabular}{|c|c|c|c|c|c|c|c|c|c|c|c|c|c|c|}
\hline Variable & Mean & s.d. & 1 & 2 & 3 & 4 & 5 & 6 & 7 & 8 & $\mathbf{9}$ & 10 & 11 & 12 \\
\hline 1. Financial orientation & 0.28 & 0.19 & & & & & & & & & & & & \\
\hline 2. Strategic orientation & 0.02 & 0.04 & -.00 & & & & & & & & & & & \\
\hline 4. Sectoral diversification & 0.76 & 0.25 & .03 & .06 & -.01 & & & & & & & & & \\
\hline 5. Practice-specific experience & 0.15 & 0.29 & .06 & -.11 & .10 & -.12 & & & & & & & & \\
\hline 6. Fit-specific experience-Organizational & 0.63 & 0.40 & .09 & -.01 & .04 & .11 & -.27 & & & & & & & \\
\hline 9. Firm size ${ }^{b}$ & 7.90 & 2.38 & .07 & .07 & .17 & .27 & .03 & -.12 & -.09 & .37 & & & & \\
\hline 10. Firm slack & 0.69 & 0.64 & -.06 & .06 & -.02 & -.18 & -.17 & .03 & .18 & -.10 & -.43 & & & \\
\hline 11. Firm performance & 0.78 & 2.69 & .09 & .08 & .09 & .19 & .01 & .12 & .04 & .38 & .38 & -.05 & & \\
\hline 12. CVC experience ${ }^{\mathrm{b}}$ & 2.86 & 1.27 & .25 & .09 & -.06 & .74 & -.04 & .04 & -.15 & .40 & .39 & -.20 & .36 & \\
\hline 13. CVC duration & 7.32 & 5.61 & .37 & .05 & -.10 & .25 & .01 & .02 & .02 & .58 & .36 & -.09 & .35 & .44 \\
\hline
\end{tabular}

\footnotetext{
a $n=375$
}

b Logarithm. 
CVC practices, controlling for time-varying omitted variables to a large extent.

For each of the four dependent variables, we estimated an equation of the form

$$
\begin{aligned}
y_{i t}=\alpha y_{i t-1}+\beta \boldsymbol{X}_{i t}+\gamma \boldsymbol{Z}_{i t} & +\eta_{i}+\varepsilon_{i t} ; \\
t & =1,2, \ldots, T ;|\alpha|<1
\end{aligned}
$$

where $\alpha$ is the autoregressive parameter on the lagged dependent term $y_{i t-1}, \eta_{i}$ is the firm-specific fixed effect, $\beta$ s are the coefficients of interest, $\boldsymbol{X}$ is a vector of our three main independent variables, and $\boldsymbol{Z}$ is the vector of controls. In this specification, $\beta$ is the short-run effect of an independent variable, and $\frac{\beta}{(1-\alpha)}$ is the long-run effect of the same variable. ${ }^{11}$

Simple ordinary least squares (OLS) coefficient estimates are biased by the presence of $\eta_{i}$ (the firm fixed effect), while the fixed effects within-firm estimator, is consistent only in panels where the time dimension $T$ is large; the transformed lagged dependent variables are correlated with the transformed error term, but this correlation goes to zero only for large T's. In our data set, this is not the case, because we have on average six years of data for each firm. Therefore, we use the Arellano-Bond difference estimator (Arellano \& Bond, 1991; HoltzEakin, Newey, \& Rosen, 1988), which is designed for dynamic panels with a short time dimension ( $T$ $\leq 10$ ) and a larger firm dimension. The ArellanoBond difference estimator employs the technique of generalized method of moments (GMM), which has an additional advantage over least-squares techniques for proportion measures: it does not require the normality of the residuals, so it can be easily applied to dependent variables that are proportion measures or are censored (as is the case for the Herfindahl index), since GMM yields consistent and asymptotically normal estimates (Hansen, 1982). Bond (2002) provides a detailed exposition of the methodology.

Estimation proceeds by first differencing the data, which eliminates the firm-specific effects $\eta_{i}$ from the model. First-differencing gives ${ }^{12}$

$$
\Delta y_{i t}=\alpha \Delta y_{i t-1}+\beta \Delta \boldsymbol{X}_{i t}+\gamma \Delta \boldsymbol{Z}_{i t}+\Delta \varepsilon_{i t} .
$$

Even though first-differencing eliminates the fixed effect, we still needed to account for two

\footnotetext{
${ }^{11}$ In the long-run steady-state $y_{i t}=y_{i t-1}=y^{*}$ so $y^{*}=$ $\alpha y^{*}+\beta \boldsymbol{X}_{i t}+\gamma \boldsymbol{Z}_{i t}+\eta_{i}+\varepsilon_{i t} \Rightarrow \frac{\delta y^{*}}{\delta \boldsymbol{X}}=\frac{\beta}{(1-\alpha)}$

${ }^{12}$ An important advantage of first-differencing is that it does not use multiple degrees of freedom to account for fixed effects.
}

endogeneity concerns. First, $\Delta y_{i t-1}$ is correlated necessarily with $\Delta \varepsilon_{i t}$ since $y_{i t-1}$ is correlated with $\varepsilon_{i t-1}$. Second, our key independent variables may be endogenous $\left(\boldsymbol{X}_{i t}\right.$ may be correlated with $\varepsilon_{i t}$ which, in turn, implies that $\Delta \boldsymbol{X}_{i t}$ is correlated with $\Delta \varepsilon_{i t}$ ), even when we account for time-invariant fixed effects. For instance, consider a firm that has purely strategic objectives for its CVC unit. At some point, it might suddenly be inclined toward financial objectives when it observes a buoyant IPO market or the significant financial returns that IVCs are generating by taking their portfolio companies public. It may then be inclined to change both the personnel staffing of its CVC unit and its investment goals. The time-invariant firm fixed effects would not pick up this shift in objectives. CVC incentive compensation schemes could also affect investment strategies and goals, and these could also be a source of endogeneity if they varied over time for a given firm. Third, we had Directory information for only three years, so our unit-level career background measures did not include potential CVC managers whose tenure did not cover those three years. We did collect actual start and end dates for each manager's CVC job and used them to calculate the career background variables for our panel data. However, to the extent that there are managers who do not appear in the data, or errors or omissions in the biographical data we collected measurement error could be present in the career background variables; such error could bias estimates if the omissions were nonrandom. To deal with all of these endogeneity concerns for $\Delta \boldsymbol{X}_{i t}$ (as well as for $\Delta y_{i t-1}$ ) and to account for potential measurement error in the main independent variables, we employed instrumental variables. We identified valid instruments-variables that are orthogonal (independent) to the transformed error terms but are correlated with the potentially troublesome variables. Arellano and Bond (1991) showed that, provided the error term $\varepsilon_{i t}$ is serially uncorrelated and $T \geq 3$, the differenced-lagged dependent variable $\Delta y_{\text {it-1 }}$ may be instrumented by appropriately lagged levels of $y_{i}$. They showed that the following moment conditions are valid:

$$
E\left\lfloor y_{i t-s} \Delta \varepsilon_{i t}\right\rfloor=0 ; s \geq 2 ; t=3,4, \ldots, T .
$$

For the independent variables, we allowed $\boldsymbol{X}_{i t}$ to be correlated with past error terms $\varepsilon_{i t-s}$ and the current error term $\varepsilon_{i}$, but uncorrelated with future error terms $\varepsilon_{i t+s}$, for $s \geq 1$. From Arellano and Bond (1991), this implies that values of $\boldsymbol{X}^{\prime}$ 's, lagged two periods or more, are available as instruments. In 
turn, this implies that the following additional moment conditions apply: ${ }^{13}$

$$
E\left\lfloor\boldsymbol{X}_{i t-s} \Delta \varepsilon_{i t}\right\rfloor=0 ; s \geq 2 ; t=3,4, \ldots, T .
$$

Arellano (2003) showed that an overfitting bias caused by instrument proliferation in dynamic panels may be a concern. To mitigate this concern, we used only two lags as instruments in the moment conditions. To control for heteroskedasticity, we reported results using the two-step GMM estimator and employed a finite-sample correction to the two-step covariance matrix (Windmeijer, 2005). Finally, we performed an array of specification tests suggested in Arellano and Bond (1991) to examine the validity of our instruments.

In sum, the Arellano-Bond difference estimator allows us to estimate a dynamic model using the lagged variable as a regressor, account for unobserved firm fixed effects via first-differencing, and resolve the endogeneity problems inherent in our setting, and it is easily applied to truncated or bounded dependent variables. We used the "xtabond" command in STATA for estimating Equation 2 for each dependent variable.

\section{RESULTS}

\section{Main Analysis}

Table 2 shows estimates for models of CVC goal orientation (models 1 and 2) and CVC operational strategies (models 3 and 4). For practice-specific career experience, Hypothesis 1a predicts that CVC units with higher proportion of CVC managers with IVC experience will be more oriented toward financial goals. Model 1 shows that an increase in the fraction of CVC unit personnel with IVC experience leads to greater financial orientation-that is, an increase in start-ups' exits via IPO or acquisition. At the same time, model 2 shows that these CVC units are also less likely to be strategically oriented, in that their parent firms are less likely to acquire the start-ups they have invested in. Thus, we observe less modification of the goal orientation of the adopted practice, supporting Hypothesis 1a. In terms of effect size, we find that for goal orientation, a one standard deviation increase in the proportion of CVC managers with IVC experience increases the proportion of exits via IPO and thirdparty acquisitions by 0.01 in the short run and by 0.013 in the long run. For the median firm, this is equivalent to a 3.1 percent increase in financial

\footnotetext{
${ }^{13}$ Using lagged terms reduced the number of observations to 375 and entailed the loss of two firms from our sample.
}

orientation in the short run and a 4.0 percent increase in the long run. In contrast, a one standard deviation increase in IVC experience reduces strategic orientation by 1.96 percent in the short run and by 4.17 percent in the long run. The large coefficients on the lagged dependent variables for strategic orientation imply that the impact of a one standard deviation change in the independent variables is nearly twice as large in the long run as the short run.

Next, models 3 and 4 provide estimates for CVC operational strategies. Hypothesis $1 \mathrm{~b}$ states that the higher the proportion of CVC managers with IVC experience, the less the operational strategies of their CVC unit will be modified. Models 3 and 4 provide strong support for Hypothesis 1b, showing that an increase in the proportion of IVC experience in a CVC unit results in an increase in the proportion of early-stage investments and in the industry diversity of investments. Such operational strategies are aligned with IVC practices, indicating less modification in the operational strategies of the adopted practice. Our estimates imply that a one standard deviation increase in IVC background leads over time to an increase in the respective proportions of early-stage investments and sectoral diversification of 0.016 and 0.01 in the short run and of 0.021 and 0.02 in the long run. For the median firm, this is equivalent to more than a 15 percent increase in the proportion of early-stage investments and a 1.8 percent increase in diversification in the long run.

For organizational fit-specific career experience, Hypothesis 2a predicts that CVC units with a higher proportion of CVC managers with adopting firm-specific experience are more likely to modify the goals of the practice. We find that an increase in the proportion of internal hires in a CVC unit results in lower financial orientation (model 1) and a higher strategic goal orientation (model 2), thereby supporting Hypothesis 2a. Here, a one standard deviation increase in the proportion of internal hires reduces the proportion of exits via IPOs and acquisitions by 0.04 in the short run and by 0.05 in the long run, and it raises the proportion of own acquisitions by 0.04 in the short run and by 0.08 in the long run. For the median firm, this amounts to a 15 percent reduction in financial orientation and a 4 percent increase in strategic orientation in the long run.

Hypothesis $2 \mathrm{~b}$ states that CVC units with a higher proportion of managers who have adopting firmspecific experience are more likely to modify the operational strategies of their CVC unit. Model 3 shows that an increase in the proportion of internal hires leads to an increase in the proportion of early- 
TABLE 2

Arellano-Bond Estimates of the Impact of Career Background on CVC Goal Orientation and Operational Strategies ${ }^{\mathrm{a}}$

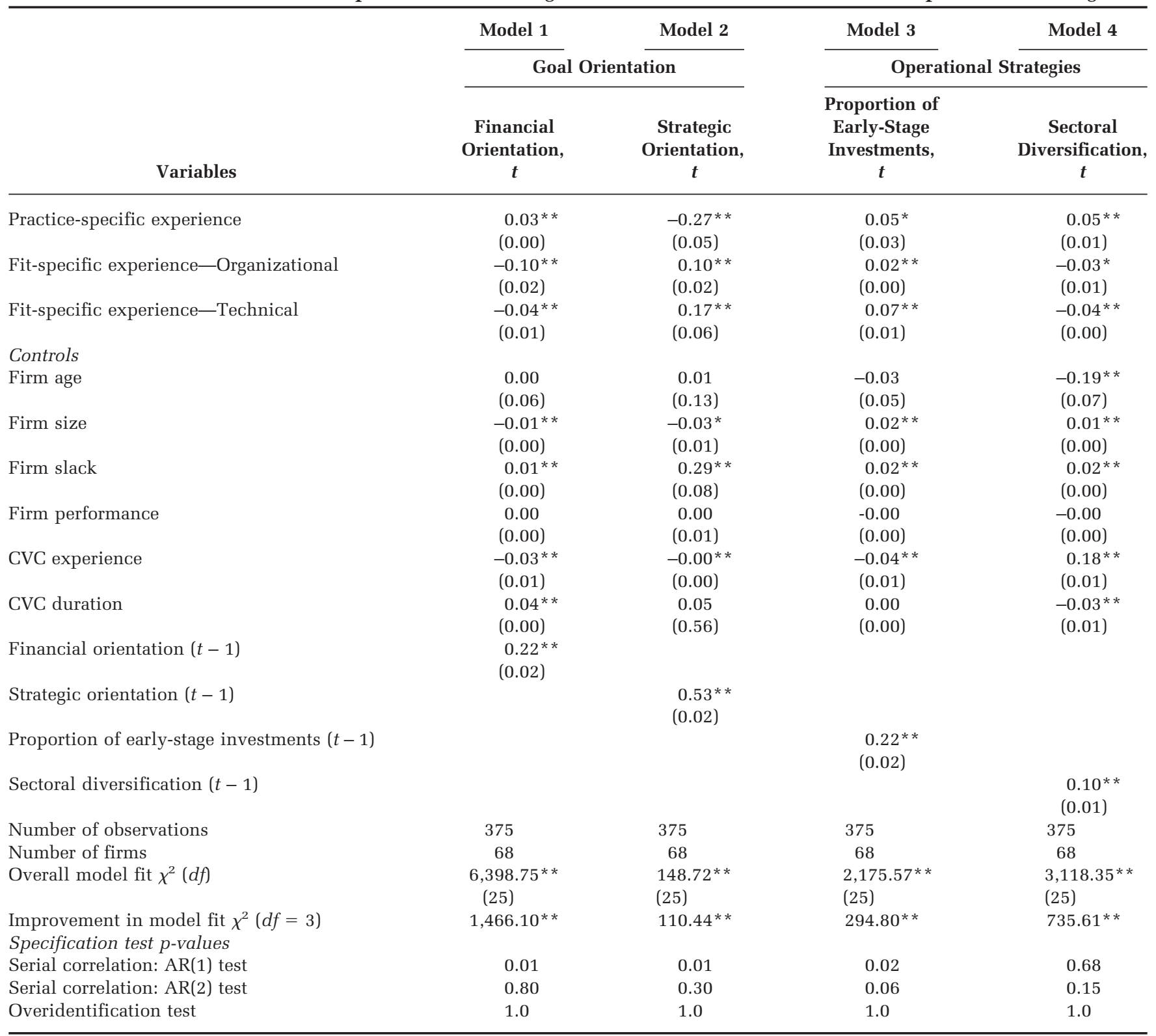

${ }^{a}$ Robust standard errors are in parentheses. All columns include year dummies; all variables are in first-differences, which account for firm-fixed effects. The lagged differenced dependent variable and the career background variables are instrumented by their higher lagged levels. The last three rows report specification tests for the Arellano-Bond difference estimator.

${ }^{*} p<.05$

$* * p<.01$

stage start-up investments, which is consistent with standard IVC practice, thus contradicting Hypothesis $2 \mathrm{~b}$. However, model 4 also shows that CVC units invest in a narrower range of industry sectors, as hypothesized. Together, we find mixed support for Hypothesis 2b. A one standard deviation increase in proportion of internal hires results in a 6 percent increase in the proportion of early-stage investments and a 1.7 percent decline in diversification in the long run for the median firm.
For technical fit-specific experience, Hypothesis 3a predicts that an increase in the proportion of CVC managers with engineering experience will lead to more strategically oriented CVC units. We find that an increase in the proportion of personnel with an engineering background in a CVC unit leads to a lower financial and a higher strategic goal orientation, supporting Hypothesis 3a. Our estimates imply that a one standard deviation increase results in a 6 percent reduction in financial orien- 
tation and a 7.3 percent increase in strategic orientation in the long run for the median firm.

In Hypothesis 3b, we predict that operational strategies of CVC units are more likely to be modified in CVC units with a higher proportion of CVC managers having engineering experience. Like our internal hires hypothesis, Hypothesis $3 \mathrm{~b}$ received mixed support. An increase in the proportion of managers with engineering experience in a CVC unit leads to a higher proportion of investments in early-stage start-ups (model 3), suggesting no variation from standard IVC practice on this particular operational dimension. However, model 4 shows that these CVC units also invest in a diverse range of start-ups, as predicted in Hypothesis 3b. Here, a one standard deviation increase in the proportion of engineers results in an increase (decrease) in the proportion of early-stage ventures (diversification) by $0.02(0.01)$ in the short run and by $0.03(0.02)$ in the long run. For the median firm, this reflects a 27 percent increase in the proportion of early-stage companies in the long run and a 1.9 percent decrease in diversification in the long run.

In all four models, we observed that the lagged dependent variables are positive and significant, showing persistence in CVC goal orientation and operational strategies. Each of the models in Table 2 reports a Wald test for overall model fit showing that all variables are jointly significant in models $1-4$, and each model is a significant improvement over a constant-only model. The next Wald test (improvement in model fit) shows that the three career experience variables result in a significant improvement of model fit compared to a baseline model that includes only the control variables. Finally, the last three rows in Table 2 report $p$-values from three specification tests suggested by Arellano and Bond (1991). The tests indicate that the original error term $\varepsilon_{i t}$ is serially uncorrelated, since the $p$-values exceed 0.05 for each of the AR(2) tests, so that the moment conditions are well-specified. Sargan overidentification tests suggested that our instruments are orthogonal to the error term and supported the validity of our instruments.

\section{Robustness Checks}

In the main analysis, we tracked both the portfolio of each CVC unit and the CVC background variables from the date of establishment of the unit. However, as explained earlier, there is a possibility of measurement error for our independent variables of interest. We accounted for this by using the lagged dependent variable as a regressor and by instrumenting each of the career background variables; however, as a robustness check, we reesti- mated the models, restricting the time span of the data to 2000-02. This restriction addressed measurement error in the CVC background variables but introduced the possibility that the portfolio over the period 2000-02 might have been set in motion by managers who left prior to 2000 . The use of the lagged dependent variable alleviated this concern to a large extent, since it recognized that the characteristics of the portfolio in the year 2000 are a function of the portfolio's characteristics in the previous year. Our results (available from the authors upon request) are robust to the restricted time frame.

We also split our sample into two subgroups based on the median age of a CVC unit. The results for the subsamples did not reveal any consistent differences, and our results continued to be supported in both subsamples, suggesting that the effect of career experience is similar for both newer CVC units and older CVC units.

\section{DISCUSSION}

The primary objective of this study was to investigate the effect of individuals' career experiences on the extent of practice variation. The institutional perspective on practice adoption, with its theoretical emphasis on isomorphism, has only started to go beyond adoption decisions to examine postadoption variation. Recent studies have suggested field-level and organizational influences that lead to practice variation (e.g., Kennedy \& Fiss, 2009; Lounsbury, 2001, 2007); however, qualitative case studies of practice adoption have suggested that individuals who implement and manage practices also play an important role in their interpretation and translation (Boxenbaum \& Battilana, 2005; Morris \& Lancaster, 2006; Zbaracki, 1998). The current study extends theory on practice variation by providing a systematic way of predicting the influence of individuals on the extent of practice variation. We develop a theoretical framework that specifies practice-specific and fit-specific prior career experiences of implementing managers as predictors of how much practices will vary after adoption. Further, our analytical approach estimates a dynamic model with firm fixed effects, accounts for endogeneity concerns in our key independent variables, and uses instrumented lagged dependent variables to capture persistence in CVC practices (Arellano \& Bond, 1991). This, in turn, enables us to show individual-level effects over and above any organizationlevel effects. 
We conceptualized the extent of practice variation in terms of both goal orientation and operational strategies of practices. Drawing on organizational learning theory, we argued that different types of career experiences confer specific knowledge and mental models that in turn influence practice variation. Practice-specific experience leads to a more faithful replication of an adopted practice, while fit-specific experience enables assessment of fit between the practice and the adopter, leading to greater modification of the adopted practice. We tested hypotheses based on these arguments by examining the implementation of IVC practices by CVC managers from 70 CVC units from 1992 through 2008. Our analysis provides broad support for our predictions and for the usefulness of examining individual effects on practice variation using a framework of practice- and fit-specific career experience.

\section{The Role of Individuals in Practice Variation}

First, we find that CVC units staffed with managers having practice-specific experience (that is, IVC experience), show a financial goal orientation and a propensity to invest in early-stage start-ups and in diverse industries, in keeping with the IVC practice blueprint (Gompers \& Lerner, 2004). For fit-specific experience, we investigated two types of career experience that would enable assessment of organizational and technical fit between practice and adopter: firm-specific experience and engineering experience. We found that CVC units staffed with managers having these types of experience resulted in modification of the goal orientation of the practice from financial to strategic, as expected. However, results for the modification of operational strategies were mixed. Although increasing firm-specific experience and increasing engineering experience in a CVC unit were significantly associated with investments in a narrower range of industries, both of these types of experience were related to investments in early-stage start-ups. That is, having career experience that enables assessment of fit between a practice and an adopting organization is strongly related to practice variation for the outcome of goal orientation, but only for one measure of operational strategy.

The mixed results for the effect of fit-specific career experience on operational strategies suggest that a more nuanced view of operational strategies underlying practices is in order. Why wouldn't all operational strategies be subject to the same pressures for practice variation? One possible explanation is that operational strategies may not be clas- sifiable into a single category, but should perhaps be considered along additional dimensions. For example, certain operational strategies may be so central to the overall conception of a practice that implementing managers do not consider alternatives. Venture capital is distinct from other forms of financing because VCs specialize not only in providing funds to young start-ups, but also in guiding them through early stages of development (Gompers \& Lerner, 2004). Accordingly, for venture capital investment, the operational strategy of earlystage investing may be integral to the practice of selecting investment targets. Alternatively, certain operational methods of a practice could be equally applicable to different contexts and may require minimal or no modification. Because CVC activity is often used to complement in-house $\mathrm{R} \& \mathrm{D}$, the operational strategy of investing in early-stage startups could accelerate access to emerging technologies and markets and enable increased knowledge creation and a higher rate of technological innovation. Future research should further explore different types of operational strategies and their adaptation to new contexts.

Examining the pattern of results across models, we also find that differing goal orientations for CVC managers might result in outcomes that need to be traded off against each other. Specifically, we expected the proportion of implementing managers with practice-specific experience to positively affect financial goal orientation, but we also found that it negatively affects strategic goal orientation. Similarly, we found that although fit-specific experience positively affects the strategic goal orientation of CVC units, it also negatively affects their financial orientation. We did not hypothesize such a trade-off; however, there is some conceptual support for it. Managerial attention is a limited resource (Simon, 1976), so restriction of attention to a financial orientation might preclude attention to strategic concerns, and vice versa. Even if CVC units could have only one orientation, strategic and financial goal orientations are not necessarily at odds. A strategically valuable acquisition could be financially neutral or even provide financial benefit, or investments that pay off with financial returns can yield strategically valuable technological knowledge. Moreover, the negative and significant relationship between our variables for practice-specific experience and strategic orientation suggests a tension between practice expertise and the needs of adopting firms. Hiring practice experts would seem to be a sensible way of implementing new practices, yet our results suggest that they may exhibit cognitions and behaviors 
more suitable to an IVC context than to a corporate context. Future work could explore the relationship between financial and strategic orientations, goals, and outcomes to understand the conditions under which trade-offs occur.

\section{Exploring Practice Variation across Levels of Analysis}

Our study extends theory on practice adoption and variation by focusing on individual-level determinants. We confined our interest to individual-level determinants to the extent that we controlled extensively for contextual elements, including fixed effects that removed stable characteristics of the adopting organizations from consideration, time-varying organizational and unit controls, and lagged dependent variables that accounted for persistence and path dependency in CVC practices. By holding organizational context strongly constant, we have shown that individual-level effects operate over and above any effects at higher levels of analysis. However, organizational and institutional factors have also been shown to affect practice variation, and we missed an opportunity to consider how these determinants at multiple levels of analysis may interact. For example, Lounsbury (2001) found that field-level ecological organizations influenced the way in which colleges implemented recycling programs. Similarly, field-level organizations such as professional associations may change how implementing managers apply their career experiences to adopted practices. For instance, professional associations for venture capitalists may provide a vehicle for CVC managers with engineering backgrounds to meet and learn from IVCs, counteracting the influence of their fit-specific experience. On the other hand, such an association could positively interact with IVC backgrounds to reduce variation in venture capital practices even further.

Another way that individual- and organizationlevel factors could interact concerns existing organizational practices. In their application of agency theory to CVC investment, Dushnitsky and Shapira (2010) found that higher-powered, incentive-based compensation schemes are associated with earlier-stage investment for CVC units. Organizational compensation schemes may interact with career background in interesting ways. High-powered incentive compensation is congruent with IVC practices, so CVC managers with fit-specific experience may instigate less practice variation in goal orientation and operational strategies in organizations that use such incentives. An implication for studies of practice variation is that existing practices of adopting organization may be more or less aligned with the source of the adopted practice, reducing the need to vary practices to fit.

\section{Limitations and Directions for Future Study}

We have theorized that prior experience conditions specific knowledge and mental models that drive the extent of practice variation. However, our archival methods in this study did not allow for direct examination of the individuallevel mechanisms that drove variation. Rather than mechanisms that involve learning and cognition, mechanisms having to do with other individual-level characteristics might actually be the causal factor. For instance, prior experience conditions social identity and social networks as well as knowledge and mental models, and the propensity to modify practices might be a function of whom CVC managers have strong social ties to or identify with, as opposed to what they know from their own past experiences. Research to tease apart these individual-level mechanisms would be challenging to conduct, but it would involve direct contact with individuals to understand the way they think about their prior careers and how they interact with others. Next, unique features of the practice we studied may have influenced our findings. VC practices are known to be complex and poorly theorized (Gaba \& Meyer, 2008), so that implementers in a corporate context need to translate the broad directives of the practices into operational actions. Thus, our results may not generalize to practices that are more thoroughly theorized or that entail fewer opportunities for job crafting or role innovation (Van Maanen \& Schein, 1979; Wrzesniewski \& Dutton, 2001). Finally, our research aggregated the experiences of personnel in CVC units, allowing us to separately examine different dimensions of experience for all personnel, but it neglects potentially interesting effects of grouplevel variables, such as the heterogeneity of functional experience or prior employers, both of which have been shown to affect organizationlevel outcomes (Beckman, Burton, \& O'Reilly, 2007; Higgins \& Gulati, 2006). Though CVC units do not function as interdependent teams in the way that top management teams or cross-functional teams do, examining how the backgrounds of CVC managers interact within a unit might be interesting for future study. 
Career Backgrounds, Human Capital, and Corporate Venture Capital

Our study primarily contributes to the understanding of practice variation; however, the findings also have implications for research on the portability of human capital across organizational boundaries. Studies in organizational learning find that individuals bring their human capital with them when they move to a new employer, adding diverse knowledge and perspectives that result in innovation (Rao \& Drazin, 2002; Song, Almeida, \& Wu, 2003). Our findings suggest that career experiences outside of a current firm may actually lead to less innovation in practices if a new hire has prior experience with the practice. Second, human capital studies have emphasized firm boundaries as an impediment to the portability of experience from one context to another (Groysberg et al., 2008; Huckman \& Pisano, 2006). Our findings indicate that experience in a practice or occupation also confers specific knowledge that is portable across firm boundaries. Our emphasis on career experience is also consistent with upper echelons theory, which addresses the functional backgrounds of CEOs as sources of the knowledge and mental models that influence strategic change in organizations (Boeker, 1997; Geletkanycz \& Hambrick, 1997). We provide evidence that the influence of career experience on organizational outcomes can be extended beyond upper echelons to subunits and lower hierarchical levels of firms. Finally, our attention to the whole careers of individuals suggests interesting extensions of current work on individual experience and organizational outcomes. Rather than treating individuals as belonging to a single occupation or employer, we capture experiences that reflect the complexity and diversity of modern careers (Bidwell \& Briscoe, 2010).

In addition, recent research in corporate venture capital has provided insights into the role that CVC units play in the business and innovation strategies of firms (Dushnitsky \& Lenox, 2006); however, relatively little is known about the determinants of CVC unit investment practices. Our study supplements the CVC literature by showing that the career backgrounds of individuals managing CVC units are consequential for how these units conduct venture capital practices.

Our study presents additional evidence that the specific characteristics of individuals shape the activities and outcomes of the firms that employ them. Rather than presenting an image of abstract organizational actors, we bring individ- uals into the foreground as important players in postadoption practice variation. Specifically, individuals' career experiences influence the extent to which adopting firms modify practices. Diffusing practices are not necessarily adopted without adjustment; they can be transformed by the managers who implement them.

\section{REFERENCES}

Abernathy, W. J., \& Utterback, J. M. 1978. Patterns of industrial innovation. Technology Review, 80(7): $40-47$.

Abrahamson, E., \& Rosenkopf, L. 1997. Social network effects on the extent of innovation diffusion: A computer simulation. Organization Science, 8: 289-309.

Almeida, P., Dokko, G., \& Rosenkopf, L. 2003. Startup size and the mechanisms of external learning: Increasing opportunity and decreasing ability? Research Policy, 32: 301-315.

Ansari, S. M., Fiss, P. C., \& Zajac, E. J. 2010. Made to fit: How practices vary as they diffuse. Academy of Management Review, 35: 67-92.

Arellano, M. 2003. Panel data econometrics. Oxford, U.K. \& New York: Oxford University Press.

Arellano, M., \& Bond, S. 1991. Some tests of specification for panel data: Monte-Carlo evidence and an application to employment equations. Review of Economic Studies, 58: 277-297.

Argote, L. 1999. Organizational learning: Creating, retaining, and transferring knowledge. Boston: Kluwer Academic.

Arthur, M. B., \& Rousseau, D. M. 1996. The boundaryless career: A new employment principle for a new organizational era. New York: Oxford University Press.

Audia, P. G., \& Greve, H. R. 2006. Less likely to fail: Low performance, firm size, and factory expansion in the shipbuilding industry. Management Science, 52: 83-94.

Beckman, C. M., \& Burton, M. D. 2008. Founding the future: Path dependence in the evolution of top management teams from founding to IPO. Organization Science, 19, 3-24.

Beckman, C. M., Burton, M. D., \& O’Reilly, C. 2007. Early teams: The impact of team demography on VC financing and going public. Journal of Business Venturing, 22: 147-173.

Benson, D., \& Ziedonis, R. H. 2010. Corporate venture capital and the returns to acquiring portfolio companies. Journal of Financial Economics, 98: 478499.

Bidwell, M., \& Briscoe, F. 2010. The dynamics of interor- 
ganizational careers. Organization Science, 21: 1034-1053.

Birkinshaw, J., Hamel, G., \& Mol, M. J. 2008. Management innovation. Academy of Management Review, 33: 825-845.

Boeker, W. 1997. Executive migration and strategic change: The effect of top manager movement on product-market entry. Administrative Science Quarterly, 42: 213-236.

Boh, W. F., Slaughter, S. A., \& Espinosa, J. A. 2007. Learning from experience in software development: A multilevel analysis. Management Science, 53: 1315-1331.

Bond, S. 2002. Dynamic panel data models: A guide to micro data methods and practice. Portugese Economic Journal, 1: 141-162.

Boxenbaum, E., \& Battilana, J. 2005. Importation as innovation: Transposing managerial practices across fields. Strategic Organization, 3: 355-383.

Boxenbaum, E., \& Jonsson, S. 2008. Isomorphism, diffusion and decoupling. In K. Sahlin-Andersson, R. Greenwood, C. Oliver, \& R. Suddaby (Eds.), The Sage handbook of organizational institutionalism: 218-242. Los Angeles \& London: Sage.

Bromiley, P. 1991. Testing a causal model of corporate risk-taking and performance. Academy of Management Journal, 34: 37-59.

Burton, M. D., Sorensen, J. B., \& Beckman, C. 2002. Coming from good stock: Career histories and new venture formation. In M. Lounsbury \& M. Ventresca (Eds.), Research in the sociology of organizations: Social structure and organizations revisited, vol. 19. Greenwich, CT: JAI Press.

Campbell, J. L. 2005. Where do we stand? Common mechanisms in organizations and social movements research. In G. F. Davis, D. McAdam, W. R. Scott, \& M. Zald (Eds.), Social movements and organization theory. New York: Cambridge University Press.

Carlile, P. R. 2004. Transferring, translating, and transforming: An integrative framework for managing knowledge across boundaries. Organization Science, 15: 555-568.

Chesbrough, H. 2003. Open innovation: The new imperative for creating and profiting from technology. Boston: Harvard Business School Press.

Coburn, C. E. 2004. Beyond decoupling: Rethinking the relationship between the institutional environment and the classroom. Sociology of Education, 77: 211-244.

Czarniawska-Joerges, B., \& Sevón, G. 2005. Global ideas: How ideas, objects and practices travel in a global economy. Malmö; \& Herndon, VA: Liber; Copenhagen Business School Press.

Dacin, M. T., Goodstein, J., \& Scott, W. R. 2002. Institu- tional theory and institutional change: Introduction to the special research forum. Academy of Management Journal, 45: 45-56.

Davis, G. F., \& Greve, H. R. 1997. Corporate elite networks and governance changes in the 1980s. American Journal of Sociology, 103: 1-37.

Dewar, R. D., \& Dutton, J. E. 1986. The adoption of radical and incremental innovations-An empirical-analysis. Management Science, 32: 1422-1433.

Dokko, G., Wilk, S. L., \& Rothbard, N. P. 2009. Unpacking prior experience: How career history affects job performance. Organization Science, 20: 51-68.

Dushnitsky, G., \& Lenox, M. J. 2005. When do firms undertake R\&D by investing in new ventures? Strategic Management Journal, 26: 947-965.

Dushnitsky, G., \& Lenox, M. J. 2006. When do incumbents learn from entrepreneurial ventures? Corporate venture capital and investing firm innovation rates. Research Policy, 34: 615-639.

Dushnitsky, G., \& Shapira, Z. 2010. Entrepreneurial finance meets organizational reality: Comparing investment practices and performance of corporate and independent venture capitalists. Strategic Management Journal, 31: 990-1017.

Dushnitsky, G., \& Shaver, J. M. 2009. Limitations to interorganizational knowledge acquisition: The paradox of corporate venture capital. Strategic Management Journal, 30: 1045-1064.

Ernst \& Young. 2008. Global corporate venture capital survey, 2008-09.

Ferlie, E., Fitzgerald, L., Wood, M., \& Hawkins, C. 2005. The nonspread of innovations: The mediating role of professionals. Academy of Management Journal, 48: 117-134.

Fiss, P. C., \& Zajac, E. J. 2004. The diffusion of ideas over contested terrain: The (non)adoption of a shareholder value orientation among German firms. Administrative Science Quarterly, 49: 501-534.

Gaba, V., \& Meyer, A. D. 2008. Crossing the organizational species barrier: How venture capital practices infiltrated the information technology sector. Academy of Management Journal, 51: 976-998.

Geletkanycz, M. A., \& Hambrick, D. C. 1997. The external ties of top executives: Implications for strategic choice and performance. Administrative Science Quarterly, 42: 654-681.

Gioia, D. A., \& Poole, P. P. 1984. Scripts in organizational behavior. Academy of Management Review, 9: $449-549$

Gompers, P. A. 1995. Optimal investment, monitoring, and the staging of venture capital. Journal of Finance, 50: 1461-1489. 
Gompers, P. A., \& Lerner, J. 2004. The venture capital cycle (2nd ed.). Cambridge, MA: MIT Press.

Greene, W. H. 2000. Econometric analysis (4th ed.). Upper Saddle River, NJ: Prentice Hall.

Groysberg, B., Lee, L.-E., \& Nanda, A. 2008. Can they take it with them? The portability of star knowledge workers' performance. Management Science, 54: 1213-1230.

Hansen, L. P. 1982. Large sample properties of generalized-method of moments estimators. Econometrica, 50: 1029-1054.

Higgins, M. C., \& Gulati, R. 2006. Stacking the deck: The effects of top management backgrounds on investor decisions. Strategic Management Journal, 27: $1-25$.

Holtz-Eakin, D., Newey, W., \& Rosen, H. S. 1988. Estimating vector autoregressions with panel data. Econometrica, 56: 1371-1395.

Huckman, R. S., \& Pisano, G. P. 2006. The firm specificity of individual performance: Evidence from cardiac surgery. Management Science, 52: 473-488.

Jonsson, S. 2009. Refraining from imitation: Professional resistance and limited diffusion in a financial market. Organization Science, 20: 172-186.

Kennedy, M. T., \& Fiss, P. C. 2009. Institutionalization, framing, and diffusion: The logic of TQM adoption and implementation decisions among U.S. hospitals. Academy of Management Journal, 52: 897918.

Kraatz, M. S., \& Moore, J. H. 2002. Executive migration and institutional change. Academy of Management Journal, 45: 120-143.

Lant, T. K., Milliken, F. J., \& Batra, B. 1992. The role of managerial learning and interpretation in strategic persistence and reorientation-An empirical exploration. Strategic Management Journal, 13: 585608.

Levinthal, D., \& March, J. G. 1981. A model of adaptive organizational search. Journal of Economic Behavior \& Organization, 2: 307-333.

Lounsbury, M. 2001. Institutional sources of practice variation: Staffing college and university recycling programs. Administrative Science Quarterly, 46: $29-56$.

Lounsbury, M. 2007. A tale of two cities: Competing logics and practice variation in the professionalizing of mutual funds. Academy of Management Journal, 50: 289-307.

Lounsbury, M. 2008. Institutional rationality and practice variation: New directions in the institutional analysis of practice. Accounting, Organizations and Society, 33: 349-361.
Macmillan, I., Roberts, E., Livada, V., \& Wang, A. 2008. Corporate venture captial [CVC]: Seeking innovation and strategic growth. NIST GCR 08-916, National Institute of Standards and Technology, U.S. Department of Commerce.

March, J. G., \& Shapira, Z. 1987. Managerial perspectives on risk and risk-taking. Management Science, 33: 1404-1418.

March, J. G., \& Simon, H. A. 1958. Organizations. New York: Wiley.

Metrick, A., \& Yasuda, A. 2010. Venture capital and the finance of innovation (2nd ed.). Hoboken, NJ: Wiley.

Meyer, A. D., \& Goes, J. B. 1988. Organizational assimilation of innovations: A multilevel contextual analysis. Academy of Management Journal, 31: 897923.

Miner, A. S., \& Mezias, S. J. 1996. Ugly duckling no more: Pasts and futures of organizational learning research. Organization Science, 7: 88-99.

Morris, T., \& Lancaster, Z. 2006. Translating management ideas. Organization Studies, 27: 207-233.

Nigam, A., \& Ocasio, W. 2010. Event attention, environmental sensemaking, and change in institutional logics: An inductive analysis of the effects of public attention to Clinton's health care reform initiative. Organization Science, 21: 823-841.

Palmer, D. A., Jennings, P. D., \& Zhou, X. G. 1993. Late adoption of the multidivisional form by large United States corporations-Institutional, political, and economic accounts. Administrative Science Quarterly, 38: 100-131.

Rao, H., \& Drazin, R. 2002. Overcoming resource constraints by recruiting talent from rivals: A study of recruitment and product innovation in the mutual fund industry 1986-1994. Academy of Management Journal, 45: 491-507.

Sahlin, K., \& Wedlin, L. 2008. Circulating ideas: Imitation, translation and editing. In K. Sahlin-Andersson, R. Greenwood, C. Oliver \& R. Suddaby (Eds.), The Sage handbook of organizational institutionalism: 218-242. Los Angeles \& London: Sage.

Sahlin-Andersson, K. 1996. The construction of organizational fields. In B. Czarniawska \& G. Sevon (Eds.), Translating organizational change: 69-92. Berlin \& NY: Walter de Gruyter.

Shane, S., \& Khurana, R. 2003. Bringing individuals back in: The effects of career experience on new firm founding. Industrial and Corporate Change, 12: $519-543$.

Simon, H. A. 1976. Administrative behavior: A study of decision-making processes in administrative organization (3rd ed.). New York: Free Press. 
Singh, J., \& Agrawal, A. 2011. Recruiting for ideas: How firms exploit the prior inventions of new hires. Management Science, 57: 129-150.

Song, J., Almeida, P., \& Wu, G. 2003. Learning-by-hiring: When is mobility more likely to facilitate interfirm knowledge transfer? Management Science, 49: 351365.

Sorensen, J. B., \& Stuart, T. E. 2000. Aging, obsolescence, and organizational innovation. Administrative Science Quarterly, 45: 81-112.

Sorenson, O., \& Stuart, T. E. 2001. Syndication networks and the spatial distribution of venture capital investments. American Journal of Sociology, 106: 15461588.

Strang, D., \& Jung, D. I. 2009. Participatory improvement at a global bank: The diffusion of quality teams and the demise of a six sigma initiative. Organization Studies, 30: 31-53.

Strang, D., \& Meyer, J. W. 1993. Institutional conditions for diffusion. Theory and Society, 22: 487-511.

Strang, D., \& Soule, S. A. 1998. Diffusion in organizations and social movements: From hybrid corn to poison pills. In J. Hagan \& K. Cook (Eds.), Annual review of sociology, vol. 24: 265-290. Palo Alto, CA: Annual Reviews.

Van Maanen, J., \& Schein, E. H. 1979. Toward a theory of organizational socialization. In L. L. Cummings \& B. M. Staw (Eds.), Research in organizational behavior, vol. 1: 209-264. Greenwich, CT: JAI.

Venture Economics 2001. http://ventureeconomics. $\mathrm{com} /$.

Wezel, F. C., Cattani, G., \& Pennings, J. M. 2006. Com- petitive implications of interfirm mobility. Organization Science, 17: 691-709.

Windmeijer, F. 2005. A finite sample correction for the variance of linear efficient two-step GMM estimators. Journal of Econometrics, 126: 25-51.

Wooldridge, J. 2002. Econometric analysis of cross section and panel data. Cambridge, MA: MIT Press.

Wrzesniewski, A., \& Dutton, J. E. 2001. Crafting a job: Revisioning employees as active grafters of their work. Academy of Management Review, 26: 179201.

Zbaracki, M. J. 1998. The rhetoric and reality of total quality management. Administrative Science Quarterly, 43: 602-636. M

Gina Dokko (gdokko@ucdavis.edu) is an assistant professor at the Graduate School of Management at the University of California, Davis. She received her Ph.D. from the Wharton School at the University of Pennsylvania. Her research addresses the consequences of individuals' job mobility and career histories for innovation, learning, and performance.

Vibha Gaba (vibha.gaba@insead.edu) is an assistant professor of organizational behavior at INSEAD, Singapore. She received her Ph.D. in management from Lundquist College of Business at the University of Oregon. Her current research includes corporate venture capital, relationships between internal and external R\&D, and organizational change and innovation. 
Copyright of Academy of Management Journal is the property of Academy of Management and its content may not be copied or emailed to multiple sites or posted to a listserv without the copyright holder's express written permission. However, users may print, download, or email articles for individual use. 